\title{
Transformar recursos em resultados
}

Paula Broeiro*

A vida e os seus acontecimentos são cíclicos e o ciclo da minha liderança da Revista Portuguesa de Medicina Geral e Familiarterminou. A escrita deste editorial fez-me retornar a escritos que encerraram outros ciclos e sobre essa matriz (resposta a um desafio: Como éque se transformam recursos em resultados? ${ }^{1}$ escrevi o editorial deste fim, e de outros começos. Em 2013, a resposta àquela pergunta fez-me rever conceitos que, quando integrados, nos ajudam a compreender e potenciar resultados. Regresso à questão com outra profundidade conferida pela vivência enriquecedora (potenciada pela coesão, dinamismo e profissionalismo da equipa) destes três anos e materializada nos editoriais publicados no triénio, por mim, pelo John Yaphe e por todos os convidados a quem agradeço com estima.

No primeiro editorial reconheci a importância das organizações aprendentes, constituídas por pessoas que funcionam em conjunto, com confiança mútua, complementando-se nos pontos fortes e compensando-se nas limitações, aceitando que os objetivos comuns se sobrepõem aos individuais. ${ }^{2}$ Nelas a criatividade é estimulada, novas ideias são alimentadas, a aspiração coletiva é libertada e as pessoas aprendem continuamente umas com as outras. ${ }^{2}$ As organizações com futuro são estas, as que descobrem como desenvolver a capacidade de aprender das pessoas, sendo as pessoas, incluindo as lideranças, o recurso essencial aos resultados. Os líderes devem possuir inteligência emocional que lhes permita construir equipas reflexivas, estruturadas no tecido invisível das interações pessoais, comprometidas com o sucesso da organização e com a aprendizagem ao longo da vida, em que cada um potencia o todo. ${ }^{2}$ Nas organizações aprendentes, a prioridade é dada às pessoas - o recurso de sucesso.

Em saúde, as comunidades de prática são um exemplo de organização aprendente, baseiam-se nas rela-

*Directora da Revista Portuguesa de Medicina Geral e Familiar ções entre profissionais de saúde, em cuidados eficazes e centrados no paciente, na flexibilidade adquirida num ambiente de constante reavaliação da aprendizagem através de casos. Neste modelo, os profissionais definem objetivos comuns (colaborativos), criam em colaboração planos de saúde (planos cocriados) e envolvem-se numa aprendizagem e numa prática reflexivas. Os seus membros estão dispostos a aprender com a prática comum, assumir como seus os objetivos dos outros, partilhar as histórias de sucesso e fracasso, e promover a evolução contínua da aprendizagem coletiva, o que requer mecanismos de feedback adequados. ${ }^{3}$ A atualização de conhecimentos e competências - desenvolvimento profissional contínuo-perpetua a aprendizagem como complemento à prática diária $\mathrm{e}$ concretiza-se em atividades de grupo, realistas, orientadas aos desafios da prestação de cuidados e às necessidades/preferências dos profissionais, mensuráveis pelos ganhos de conhecimento, desempenho clínico e/ou melhoria dos resultados em saúde. ${ }^{3}$

Em contextos, cada vez mais, incertos e imprevisíveis, o conhecimento tem assumido uma vantagem competitiva sustentável. ${ }^{4} \mathrm{O}$ conhecimento é um recurso valioso e insubstituível enquanto força motriz organizacional. O conhecimento e a sua estruturação, tal como as aptidões, têm variabilidade individual, isto é, pessoas diferentes incorporam a informação de forma diferente e constroem os seus conhecimentos de acordo com as suas experiências e quadros de referências. ${ }^{4}$ O conhecimento, por si só, não assegura a competência clínica; contudo, a par da experiência, incorpora outras dimensões como saber fazer, saber ser, saber pensar e saber integrar- essenciais à evolução do pensamento linear para o pensamento complexo e do conhecimento para a competência, num processo cíclico e gradual em espiral, de regresso aos mesmos temas com maturidade e/ ou profundidade diferentes. ${ }^{4}$ Numa organização de prática/aprendente, conhecimento e competência são outros dos recursos que conduzirão 
à obtenção de resultados.

O contexto de exercício, comunidade de prática ou organização aprendente, e a disponibilidade (tempo) potenciam o desenvolvimento de práticas baseadas em evidência (PBE). As PBE incluem a aplicação da epidemiologia e a avaliação crítica na tomada de decisão explícita. A PBE significa integrar a experiência individual com a melhor evidência externa disponível, proveniente de investigação, aproximando-se da definição inicial de Sackett. ${ }^{5} \mathrm{O}$ processo de PBE foi descrito em etapas: tradução de incerteza numa pergunta; revisão sistemática da melhor evidência disponível; avaliação crítica da evidência (validade, relevância e aplicabilidade); aplicação dos resultados na prática e avaliação do desempenho. ${ }^{5-6} \mathrm{O}$ conceito inicial de medicina $b a$ seada na evidência (MBE) correspondia ao "uso consciente, explícito e judicioso da melhor prova na tomada de decisão no cuidado ao paciente individual". ${ }^{6} \mathrm{Num}$ editorial, Trisha Greenhalgh alerta para o paradoxo de o rigor metodológico bem-intencionado da MBE perpetuar o mito de que nos libertamos de incertezas e ambiguidades se reduzirmos a complexidade do tratamento a questões centradas sobre populações, intervenções, comparações e resultados. ${ }^{7}$ Num dos seus editoriais, John Yaphe recorda que a incerteza é um facto da vida real e que, em medicina, a sua aceitação pode ajudar a desenvolver estratégias eficazes para lidar com ela. As atitudes face à incerteza encontram-se em mudança, passando de tentativas de dominar ou diminuir a incerteza para a sua gestão. ${ }^{6}$ Outros dos recursos para obter resultados são a gestão da incerteza e o uso da prova/evidência que suporta a prática e é gerada pela prática.

Outra expressão de evidência é uma medicina praticada com competência narrativa, atitude e prática, que permite olhar para lá dos mecanismos biológicos e das abordagens convencionais, abarcando domínios de pensamento e de comunicação que se focalizam na linguagem e na representação das emoções e das relações. Reconhecer, interpretar e agir robustece-se no treino narrativo (leitura e escrita) e contribui para a eficácia clínica. ${ }^{8}$ A anamnese estabelece a ponte entre doente (sintomas e sinais) e o médico que interpreta a expressão do sofrimento, conduz o processo diagnóstico e toma decisão. Aplicando o princípio de Pareto (80\% das consequências advêm de $20 \%$ das causas), a anamnese (20\% da consulta) pode ser responsável por $80 \%$ dos diagnósticos. O exame clínico é outra etapa que torna o processo de decisão eficiente. Atualmente, o exame clínico está a ser sujeito aos mesmos critérios exigentes que qualquer outra tecnologia laboratorial ou de imagem, nomeadamente através de estudos que comparam os achados da história e exame objetivo com um padrão-de-ouro considerado diagnóstico de uma determinada doença. ${ }^{9}$ Os Médicos de Família contam histórias, autênticas biografias definindo a medicina como criação de lugar para o outro: a abertura à história do outro enquanto história de um outro. Na medicina familiar acompanham-se histórias de vida no seu acontecer pelo que é ela, por excelência, o campo onde a Medicina Narrativa deve ser vivida e praticada. ${ }^{10-11}$ Praticar no lugar uma medicina com competência narrativa, recentrar os cuidados na anamnese (doença e vivência da doença) e no exame clínico poderão trazer ganhos de eficiência e de satisfação.

Uma pessoa doente é mais que o conjunto dos seus diagnósticos e terapêuticas e requer uma abordagem holística que inclua a compreensão da singularidade resultante da interceção de sistemas (e.g., individual, familiar, social e sistema de saúde). O método clínico centrado no paciente (MCCP) define um modelo para essa abordagem holística, através da integração em sinergia da medicina, epidemiologia, psicologia, antropologia e ainda dos cuidados e cuidadores. O MCCP é uma expressão da complexidade: requer que entendamos não só a doença biológica, mas também a experiência individual de doença, contexto social amplo (família, comunidade, época) e os determinantes da saúde, a par do encontro de plataformas de entendimento, da melhoria da relação e da articulação de cuidados (e.g., sistemas de saúde). ${ }^{12-13}$ A complexidade dos doentes é potencialmente mais relevante do que a complexidade do diagnóstico, porque está frequentemente ligada a determinantes sociais de saúde e à necessidade de integração horizontal de cuidado, sendo indispensáveis o trabalho em equipa multiprofissional e uma articulação social eficientes. ${ }^{13} \mathrm{O}$ MCCP evidencia os limites do desenho de gestão orientado para a doença e realça a necessidade de mudança de paradigma para uma gestão centrada na pessoa. ${ }^{13}$ A acessibilidade, definida como "a facilidade com que uma pessoa pode obter os cuidados médicos necessários dentro do período de 
tempo adequado ao problema”, é um dos requisitos duma especialidade comunitária como a MGF ${ }^{14} \mathrm{~A}$ acessibilidade e a integração de cuidados e da complexidade encontram-se subjacentes à filosofia disciplinar de MGF, o Método Clínico Centrado no Paciente como recurso para obter resultados eficientes.

A natureza e a diversidade das tarefas do médico de família (MF) não se compadecem com restrições à sua autonomia técnico-científica, conferindo limites aos modelos industriais de gestão e à expectativa do seu controlo e previsibilidade (aspetos paradoxais dos indicadores). ${ }^{15}$ Uma autonomia técnico-científica responsável e custo-efetiva é um dever ético. Tendo presente este princípio, a ingerência de medidas gestionárias no exercício da MGF podem torná-lo crítico em áreas como: a decisão clínica (diagnóstica e terapêutica) e a abordagem da complexidade das pessoas que adoecem (e.g., doença física e mental; doença e problemas sociais). É, pois, da dissonância entre o profissionalismo médico e a impossibilidade de observância de regras rígidas (tempos de consulta, cumprimento dos indicadores) para dimensões de listas desadequadas ao contexto (organizacional e populacional) e ao profissional, aliados ao presenteísmo ${ }^{16} \mathrm{e}$ às condições de trabalho, que surgem a desmotivação e a exaustão. ${ }^{17}$ Um médico, para exercer com profissionalismo, deverá ter reconhecido o valor do seu trabalho (multidimensional, abrangente e centrado no paciente) como recurso organizacional.

É num olhar atento sobre a realidade profissional que nos surgem questões cujas respostas conduzem à atualização e à produção de conhecimento. O pensamento crítico, decorrente desse olhar atento, é complexo e ultrapassa a mera capacidade de analisar - inclui a compreensão de interações; a deteção de inconsistências; a resolução sistemática de problemas; a reflexão e a justificação de crenças e valores. Pressupõe, ainda, a reintegração da informação num todo, de preferência coerente.$^{18} \mathrm{O}$ pensamento crítico gera pensamento «fora da caixa», desafia o consenso e promove a discordância criadora. O pensamento crítico é descrito como a aplicação ao quotidiano do método científico (identificação da questão, formulação de hipótese, pesquisa e adequação do modelo de resposta). ${ }^{18}$ É um processo cognitivo intencional, aberto, rigoroso e de autocorreção. O pensar analítico e reflexivo, se cons- truído contextual e criativamente, afasta o pensamento da frieza da análise das evidências e apoia a construção do conhecimento social e cultural. ${ }^{18} \mathrm{O}$ pensamento crítico é o recurso que garante o futuro das organizações porque gera questões e cria conhecimento.

Num dos seus editoriais, John Yaphe perspetivou o paciente do futuro: tecnologicamente sábio, capaz de gerir a sua saúde, verdadeiro parceiro de decisão e integrado em comunidade de saúde. ${ }^{19}$ Contudo, alguns padrões-de-ouro provavelmente não mudarão no paciente do futuro: o contacto presencial (em momentos convenientes para o paciente) e o ser cuidado por um médico compassivo que respeite a sua dignidade e privacidade (testemunha silenciosa do seu sofrimento). ${ }^{19}$

Quem cuida precisa de ser cuidado e respeitado, cuidarbem dos profissionais de saúde será um recurso valioso e terá retorno na qualidade dos cuidados às pessoas que adoecem e às populações. A humanidade do ser médico, alicerçada no conhecimento, na experiência e no profissionalismo, refletir-se-á na qualidade da relação médico-doente, numa medicina centrada no paciente e na aceitação e gestão da incerteza e da complexidade. Enquanto especialidade atingimos maturidade e lugar nos sistemas de saúde, os quais precisam de melhorar as suas estratégias de integração e intervisão $0^{20}$ entre especialidades e profissões. Acredito numa MGF preparada para os desafios do futuro se alicerçada nos recursos enumerados, na coerência e em valores éticos.

\section{REFERÊNCIAS BIBLIOGRÁFICAS}

1. Barroso R, Fernandes A, Moeda A, Boavida H, Pisco AM, Desterro A, et al. Olhares [Internet]. Évora: CIMGFSUL; 2013. Available from: http://www.cimgfsul.org/images/fim/olhares.pdf

2. Broeiro P. 30 Anos de RPMGF como organização aprendente [Thirty years' experience with the RPMGF as a learning organization]. Rev Port Med Geral Fam. 2014;30(2):71-2. Portuguese

3. Broeiro P. Formação cocriada e colaborativa nas unidades de saúde [Cocreation and collaboration in training in family health units]. Rev Port Med Geral Fam. 2016;32(5):294-6. Portuguese

4. Broeiro P. Conhecimento e competência [Knowledge and competence]. Rev Port Med Geral Fam. 2015;31(2):82-4. Portuguese

5. Sackett DL, Rosenberg WM, Gray JA, Haynes RB, Richardson WS. Evidence based medicine: what it is and what it isn't. BMJ. 1996;312(7023):71-2.

6. Broeiro P. Prática baseada em evidência e seus limites [Evidence based medicine and its limits]. Rev Port Med Geral Fam. 2015;31(4):238-40. Portuguese

7. Greenhalgh T. Why do we always end up here? Evidence-based 
medicine's conceptual cul-de-sacs and some off-road alternative routes. J Prim Health Care. 2012;4(2):92-7.

8. Fernandes I.A pertinência da medicina narrativa na prática clínica [The relevance of narrative medicine to clinical practice]. Rev Port Med Geral Fam. 2014;32(5):289-90. Portuguese

9. Vaz-Carneiro A. Sintomas e sinais: uma abordagem científica do exame clínico [Symptoms and signs: a scientific approach to the clinical examination]. Rev Port Med Geral Fam. 2017;33(1):10-3. Portuguese

10. Ferreira-Silva JN. Criação de lugar para o outro numa medicina de "deslugar" [Creating a place for the other in a medicine of "displacement"]. Rev Port Med Geral Fam. 2015;31(4):244-5. Portuguese

11. Barroso R. Relatos de caso: para além das normas, a coerência e a congruência [Case reports: beyond norms, coherence and congruence]. Rev Port Med Geral Fam. 2016;32(4):238-40. Portuguese

12. Stewart M. Towards a global definition of patient centred care: the patient should be the judge of patient centred care. BMJ. 2001;322(7284):444-5.

13. Broeiro P. Tangibilidade da complexidade [Touching complexity in family medicine]. Rev Port Med Geral Fam. 2016;32(2):87-9. Portuguese

14. Yaphe J. Accessibility in family medicine: re-examining a core concept.
Rev Port Med Geral Fam. 2016;32(3):170-2.

15. Raposo H. Inovações organizacionais e práticas profissionais: apontamentos de reflexão sociológica [Organizational innovation and professional practice: a sociological perspective]. Rev Port Med Geral Fam. 2014;30(4):225-6. Portuguese

16. Yaphe J. Presenteeism: why we work when we are sick. Rev Port Med Geral Fam. 2015;31(4):242-3.

17. Broeiro P. Profissionalismo e políticas de gestão [Professionalism and the politics of management]. Rev Port Med Geral Fam. 2016;32(6):3668. Portuguese

18. Broeiro P. Papel social do pensamento crítico [Critical thinking and its social role]. Rev Port Med Geral Fam. 2014;30(3):147-8. Portuguese

19. Yaphe J. The future of the patient and the patient of the future. Rev Port Clin Geral. 2016;32(6):370-1.

20. Carvalho PT. Andar a par: saúde mental, psiquiatria e cuidados de saúde primários [Walking hand in hand: mental health, psychiatry, and primary]. Rev Port Med Geral Fam. 2016;32(5):300-2. Portuguese

\section{ENDEREÇO PARA CORRESPONDÊNCIA}

director@rpmgf.pt 